\title{
Status, causes and consequences of physicians' self-perceived professional reputation damage in China: a cross- sectional survey
}

Tao Sun ${ }^{1}$, Jinghui Wang ${ }^{2}$, Shu'e Zhang ${ }^{2}$, Yu Shi ${ }^{2}$, Bei Liu ${ }^{3^{*+}}$ and Xiaohe Wang ${ }^{1 *+}$ (D)

\begin{abstract}
Background: Conflict between physicians and patients is an increasingly serious problem, leading to the disrepute attached to Chinese physicians' social image and position. This study assesses the status of physicians' selfperceived professional reputation damage and explains it's the adverse outcomes including withdrawal behavior and workplace well-being. Moreover, potential causes of Chinese physicians' disrepute have been outlined.

Methods: Primary data were collected through a cross-sectional online survey of physicians from 10 provinces in China, who were invited to complete an anonymous survey from December 2018 to January 2019. A total of 842 physicians (effective response rate: 92.22\%) were recruited as participants.

Results: About $83 \%$ of the participants self-perceived professional reputation damage from the sense of the public opinion concept. Approach half of participants exhibited the idea of turnover intention (47.3\%) and one or more symptoms of burnout (46.4\%). About $74.9 \%$ of the participants experienced a degree of stress. Additionally, three out of five participants reported low-level subjective well-being. More than $70 \%$ of the participants disapproved of their offspring becoming a physician. Four factors leading to physicians' damaged professional reputations are those addressed: conflict transfer, cognitive bias, improper management, and individual deviance. Stigmatised physicians are more likely to practice high-frequent defensive medicine $(\beta=0.172, P<0.001)$, intend to leave the profession $(\beta=0.240, P<0.001)$, disapprove of their children becoming physicians $(\beta=0.332, P<0.001)$ and yield worse levels of workplace well-being, including high levels of perceived stress $(\beta=0.214, P<0.001)$, increasing burnout $(\beta=0.209, P<0.001)$, and declining sense of well-being $(\beta=-0.311, P<0.001)$.

(Continued on next page)
\end{abstract}

\footnotetext{
*Correspondence: liubei1105@163.com; xhewang@163.com

${ }^{\dagger}$ Bei Liu and Xiaohe Wang contributed equally to this work.

${ }^{3}$ Department of Epidemiology and Health Statistics, School of Public Health,

Peking University, Beijing 100191, China

${ }^{1}$ Department of Health Management to School of Medicine, Hang Zhou

Normal University, No.2318 Yuhangtang Road, Cangqian Street, Yuhang

District, Hangzhou City 311121, Zhejiang Province, China

Full list of author information is available at the end of the article
}

C C The Author(s). 2021 Open Access This article is licensed under a Creative Commons Attribution 4.0 International License, which permits use, sharing, adaptation, distribution and reproduction in any medium or format, as long as you give appropriate credit to the original author(s) and the source, provide a link to the Creative Commons licence, and indicate if changes were made. The images or other third party material in this article are included in the article's Creative Commons licence, unless indicated otherwise in a credit line to the material. If material is not included in the article's Creative Commons licence and your intended use is not permitted by statutory regulation or exceeds the permitted use, you will need to obtain permission directly from the copyright holder. To view a copy of this licence, visit http://creativecommons.org/licenses/by/4.0/. The Creative Commons Public Domain Dedication waiver (http://creativecommons.org/publicdomain/zero/1.0/) applies to the data made available in this article, unless otherwise stated in a credit line to the data. 
(Continued from previous page)

Conclusion: Chinese physicians were aware of damaged professional reputations from the sense of the public opinion concept, which contributes to increasing withdrawal behaviors and decreasing workplace well-being-a worsening trend threatening the entire health system. This novel evidence argues a proposal that Chinese health policy-makers and hospital administrators should promote the destigmatization of physicians immediately.

Keywords: Chinese physicians, Deteriorating patient-provider relationship, Damaged professional reputation, Withdrawal behavior, Workplace well-being, Cross-sectional design

\section{Background}

Ten years ago, China launched a new national health system reform with the promise to provide universal, affordable, efficient, and equitable basic health care service for all its citizens by 2020 [1]. The reform's first phase (2009-11) had given top priority to expanding social health insurance coverage for all and strengthening infrastructure. The second phase (2012 onwards) emphasised reforming its healthcare delivery system [2]. China has made substantial progress in improving equal access to care, delivering universal health coverage [3], and enhancing financial protection over the past decade [2]. As of end of 2018, China's basic medical insurance and social old-age pension schemes has covered 1.35 billion people and more than 900 million people, respectively, together constituting the largest social safety net in the world [4]. Moreover, China is seeking to rebuild the primary health-care system [5], further establishing a tiered health-care delivery system to overhaul the existing hospital-centric approach [2]. Further, its central government emphatically and authoritatively declares that a principle of reform is 'Person-Centred' [6]. 'Personcentred care', defined by McCormack et al. [7], refers to 'an approach to practice established through the formation and fostering of therapeutic relationships between all care providers, patients, and other individuals significant to them in their lives'. In this framework, all providers play an important role. More interestingly, most of the policy practices during the progress of health system reform seem to exhibit a uniform trend toward ' $\mathrm{Pa}$ tient-Centred care'. Differentiation between two health care concepts of person- and patient-centred care has been clearly confirmed and discussed [8]. Seemingly, concern regarding medical staff, especially physicians, is completely excluded from current reforms. However, without an active participation of Chinese physicians and an improvement of their social and economic status, China's health system reforms cannot be successful [9]. Physicians represent the major group in the delivery of health care services, but Chinese physicians are often victims in the new round of health system reform, facing the challenge of terrible violence [10], heavy workload, and an imbalance between effort and rewards [11]. Thus, growing attention has been focused on their unfavorable and awkward working environment [12], especially on deteriorating patient-provider relationships.

Min Zhou pointed out that four main issues, including funding shortage, an incompetent health insurance system, excessively market-oriented operation, and the media, jointly caused increasing patient-provider conflicts [13]. He further asserted that China has entered into the 'dark ages' with respect to patient-provider interaction [13]. Is it a sensational argument? It seems not to be; China's patient-provider relationships have become increasingly serious in recent years, and Chinese physicians face a high risk of harm and common safety threats at the hospital workplace [10]. A national survey carried out by research team in 2017 revealed that physicians' exposure to violence towards them is common in China; approximately $83.4 \%$ of participants had suffered more than one sort of violence [14]. Not only that, 'Yi Nao' (a Chinese term) is a unique issue in China, defined as gangs or individuals whose purpose is to force the hospital to reduce costs or to obtain compensation from hospitals, which has caused aggravating medical and hospital disturbances [15]. So far, the topic of violent incidents against medical staff and 'Yi Nao' has received extensive attention and became a source of controversy in China.

Workplace violence against physicians tend to jointly trigger a series of adverse effects on Chinese physicians, such as job dissatisfaction [16], low performance, perceived stress [17], job burnout [18], high turnover intention [16], sleep disturbance [17], poor mental health [19], and increased rate of medical error and reduced service quality [20], among others. These effects have been classified as psychological and emotional consequences that impact work functioning-main categories of outcomes arising from physicians' exposure to workplace violence or poor patient-provider relationships [20]. However, this category seems to exclude cognitive elements, which have been widely ignored in previous studies. In fact, widespread national media reporting 'bad medical news', lacking objectivity, accelerates the destruction of the trust-based patient-provider relationship [21]. As a worse result, rising disputes between physicians and patients and related negative public opinion in regard to the health care industry is likely 
to evoke a cognitive bias in the whole society, in which physicians identify themselves as being hated and maligned by public. Moreover, their self-perception of their social reputations has worsened, particularly in today's internet age. Indeed, comparing ancient and modern times, there has been a huge evolution in the perception of a physician's role in China. Physicians are no longer on a pedestal in current society [22]. Chinese physicians' incomes are low when compared with the high incomes paid in other industries that require less developed faculties or skills than medicine [23]. Public opinion that has maligned the physicians and poor compensation have bred fear among physicians [24], which contributes to physicians' cognitive change regarding damaged selfperception and appraisal of their collective reputation and social position.

Considering that a physician's social reputation is an enormously valuable asset, while the individual capability to manage his or her reputation is weak [25], selfperceived professional reputation damage among Chinese physicians tends to increase their lack of security, which results in other outcomes that have been given little attention. Previous research on reputation damage has focused mainly on special group of people with diseases such as AIDS [26], mental illness [27], tuberculosis [28], various cancers [29], obesity, diabetes, psoriasis, ADHD, epilepsy, and others. There are common similarities that these researches all discussed health-related stigmatization in patients. Indeed, reputation damage or stigmatization and its outcomes widely were investigated in patients with different kinds of diseases. The stigmatization regarding different groups is becoming a prevalent social problem in each country worldwide. Recently, extensive research has been conducted on public attitudes towards psychiatrists in Western societies [30]. In fact, people with higher social status more likely encounter common stigmatized reputation in current society, leading to an occupational stigma that staffs receive a negative reputation from public, which has caught academic attention. Moreover, reputation management strategies have been proposed in previous research [31]. However, little work has been performed on the selfperceived professional reputation damage of the physician group, which stands to benefit from an improvement in patient-provider relationship. Seemingly, this novel issue can't get attention of Chinese health policymakers and practitioner.

Due to lack social approval from patients and public, self-perceived professional reputation damage is a process by which a physician associates himself or herself with the disrepute of the vocation. The general attitudes of patients, their relatives, and public toward the physician group tend to influence the self-image and self-worth of members of the physician community in particular. There is not a single study focusing on selfperceived public attitudes toward Chinese physicians, and quantitative studies on physicians' self-perceived professional reputation damage is especially scarce. Moreover, it is important to test whether the negative consequences of self-perceived professional reputation damage among Chinese physicians persist and cause adverse effects in decision-making behavior and subjective sense of workplace well-being.

Consequently, this study aims to (1) identify the prevalence and severity level of self-perceived professional reputation damage of Chinese physicians; (2) test the association between self-perceived professional reputation damage and withdrawal behavior and workplace wellbeing; (3) identify the reasons likely to contribute to the rising public negative evaluation attached to Chinese physicians based on the physicians' own perspectives.

\section{Methods \\ Subjects and procedures}

An anonymous online questionnaire was completed by physicians across the country from December 2018 to January 2019 in China. The questionnaire was a cross-sectional survey involving 10 provinces. These physicians from Harbin Medical University were selected as 'original participants' of this survey, while the other participants included colleagues, classmates, or friends invited by them. A website link (https://www.wjx.cn/jq/31579963.aspx) about the questionnaire was sent to mobile phones of the subjects. A total of 913 participants were included in this survey, and ultimately 842 valid questionnaires were collated as analysis samples, with a $92.22 \%$ effective response rate.

The research described in this article meets the ethical guidelines of the ethics committee of the College of Public Health, Harbin Medical University. This project has been approved by the Ethics Committee of Harbin Medical University (ECHMU). Written informed consent cannot be procured because of the online and anonymous nature of the survey. Hence, oral informed consent for the survey was approved by the ECHMU and obtained from each physician. Before distributing the questionnaire, we formally informed every participant of the anonymity and privacy protection measures of the questionnaire. Dialogue and alert pop up boxes will appear on the screen of his/her mobile phone, which were used to remind participants who agreed to complete the survey to send their replies to our research group. Thus, once a questionnaire was completed, it was assumed that the physician orally agreed to participate in current survey by reference to Wen's criteria [32]. 


\section{Measures \\ Measurement of physicians' self-perceived professional reputation damage}

Single-item measures, which are easy and simple to administer, were prevalently found to be useful in areas such as health and business [33]. In current study, a single-item measure of self-perceived professional reputation damage of physicians was: 'In general, in your opinion, what is the attitude toward or evaluation on the Chinese physicians' group among patients, their relatives, and the general public?' Results were recorded on a 5-point Likert scale varying from 1'very positive' to 5 'very negative.' For the sake of clearly addressing the degree of self-perceived professional reputation damage, the scores of ' 1 ' and '2' were recoded as ' 0 ', which represents that sampled physicians have not perceived professional reputation damage from public. The scores of ' 3 ', '4', and ' 5 ' were recoded as ' 1 ', which indicates they perceived professional reputation damage from the general public.

\section{Measurement of likely causes Lead to damaged reputation}

A total of 32 items developed by the authors were used to measure the potential causes that led to patients' or public's negative impressions on Chinese physicians based on victims' (i.e. physicians') self-estimation. The response was recorded on a 5-point Likert scale varying from 1 'Strongly disagree' to 5 'Strongly agree'. Four dimensions were identified, analysed, and presented in the Results chapter of this paper, including Conflict Transfer, Cognitive Bias, Improper Management and Individual Deviance.

\section{Measurement of physicians' withdrawal behaviors}

Three items were used to measure "defensive medicine", "turnover intention", and "participants' attitudes toward the idea of their offspring becoming a physician". Three questions were jointly used to represent the physician's withdrawal behavior. The question used to monitor defensive medicine was: 'In the past year, do you practice defensive medicine to avoid medical risks or disputes during your routine clinical work?' The response was recorded on a 5-point Likert scale varying from 1 'Never' to 5 'Nearly all the time'. The question used to measure turnover intention was: 'In the past year, did you have an intention to leave your current position?' The response was recorded on a 5-point Likert scale varying from 1 'Never' to 5 'Nearly all the time'. The following single-item measure of participants' attitude toward the idea of their offspring becoming a physician was used: 'What is your attitude towards the idea of your offspring becoming a physician in future?'. The response was recorded on a 5 -point Likert scale varying from 1 'Strongly agree' to 5 'Strongly disagree'.

\section{Measurement of physicians' workplace well-being}

Three items in monitoring the "perceived stress", "job burnout", and "subjective sense of well-being" were selected to represent the workplace well-being of the sample physicians. A single-item measure of perceived stress as a more sensitive indicator of well-being in work organizational studies than illness-based health measures was developed by Elo A-L et al. [34]. This single-item measure of perceived stress had been proved to be a valid measure for drawing group-level conclusions about mental well-being [34]. The responses were recorded on a 5-point Likert scale varying from 1 'Not at all' to 5 'Very much'. Moreover, a single-item burnout question as an alternative to the Maslach Burnout Inventory in order to abbreviate survey material and potentially increase response rates, developed by Rohland, B. M. et al. [35] was used to measure burnout symptoms among sampling physicians. Another item was used to measure subjective sense of life well-being of participations. We use a 5-point Likert scale: subjective sense of well-being: $1=$ Very unhappy, 5 = Perfectly happy.

\section{Statistical analysis}

Differences in continuous variables were examined using the one-way ANOVA. Pearson's correlation coefficients were used to estimate correlations between the selfperceived professional reputation damage, withdrawn behavior, and workplace well-being. Hierarchical linear regression analysis was performed to test the effects of self-perceived professional reputation damage on these groups of dependent variables. The demographic variables related to self-perceived professional reputation damage in univariate analysis $(P<0.05)$ were entered into step 1 of the hierarchical regression analysis model in order to eliminate their interference with the dependent variables. We provided data including $F, \mathrm{R}^{2}$ and $\mathrm{R}^{2}$-changes, and the fit of the model was assessed with $\mathrm{R}^{2}$. A standardization regression coefficient $(\beta)$ and $P$ value for each step in the regression model were also produced. In this study, statistical significance was set at $P<0.05$ (two-tailed). All of the above analyses were conducted using SPSS 24.0 for Windows.

\section{Results}

Demographic information for participants and their status of self-perceived professional reputation damage

Demographic variables of participants and the ANCOVA models for the self-perceived professional reputation damage of Chinese physicians were outlined in Table 1. A total of 699 (83\%) participations thought that they had perceived that physicians to be a stigmatised group in the views of Chinese general population. Hence, current results indicated that Chinese physicians perceived their own severely damaged reputation. 
Table 1 Characteristics of the Respondents $(n=842)$

\begin{tabular}{|c|c|c|c|c|c|}
\hline Characteristics & $\mathbf{N}$ & $\%$ & $M \pm S D$ & $F / t$ & $P$ \\
\hline Self-perceived professional reputation damage & 699 & $83 \%$ & & & \\
\hline \multicolumn{6}{|l|}{ Sex } \\
\hline Male & 391 & 46.4 & $3.54 \pm 1.05$ & \multirow[t]{2}{*}{$\boldsymbol{t}=10.352$} & \multirow[t]{2}{*}{$<0.001$} \\
\hline Female & 451 & 53.6 & $3.32 \pm 0.94$ & & \\
\hline \multicolumn{6}{|l|}{ Age } \\
\hline$\leq 30$ & 196 & 23.3 & $3.31 \pm 0.92$ & \multirow[t]{4}{*}{$F=1.548$} & \multirow[t]{4}{*}{0.201} \\
\hline $31-40$ & 328 & 39.0 & $3.45 \pm 0.98$ & & \\
\hline $41-50$ & 220 & 26.1 & $3.50 \pm 1.06$ & & \\
\hline$\geq 51$ & 98 & 11.6 & $3.37 \pm 1.06$ & & \\
\hline \multicolumn{6}{|l|}{ Service Years } \\
\hline$\leq 2$ & 206 & 24.5 & $3.32 \pm 0.93$ & \multirow[t]{5}{*}{$F=0.965$} & \multirow[t]{5}{*}{0.426} \\
\hline $5-9$ & 147 & 17.5 & $3.44 \pm 1.03$ & & \\
\hline $10-14$ & 153 & 18.2 & $3.50 \pm 0.95$ & & \\
\hline $15-19$ & 75 & 8.9 & $3.36 \pm 0.82$ & & \\
\hline$\geq 20$ & 261 & 31.0 & $3.47 \pm 1.10$ & & \\
\hline \multicolumn{6}{|l|}{ Hospital level } \\
\hline Tertiary hospital & 673 & 79.9 & $3.47 \pm 1.00$ & \multirow[t]{4}{*}{$F=2.741$} & \multirow[t]{4}{*}{0.042} \\
\hline Second-class hospital & 131 & 15.6 & $3.22 \pm 0.97$ & & \\
\hline Primary hospital & 17 & 2.0 & $3.35 \pm 1.00$ & & \\
\hline Non-classified hospital & 21 & 2.5 & $3.14 \pm 0.79$ & & \\
\hline \multicolumn{6}{|l|}{ Education categories } \\
\hline College degree or below & 37 & 4.4 & $2.81 \pm 0.91$ & \multirow[t]{4}{*}{$F=5.930$} & \multirow[t]{4}{*}{$<0.001$} \\
\hline Bachelor & 410 & 48.7 & $3.39 \pm 1.02$ & & \\
\hline Master & 310 & 36.8 & $3.50 \pm 0.92$ & & \\
\hline Doctor & 85 & 10.1 & $3.55 \pm 1.12$ & & \\
\hline \multicolumn{6}{|l|}{ Marital status } \\
\hline Single & 183 & 21.7 & $3.27 \pm 0.96$ & \multirow[t]{3}{*}{$F=3.902$} & \multirow[t]{3}{*}{0.021} \\
\hline Married & 627 & 74.5 & $3.48 \pm 1.01$ & & \\
\hline Divorce or loss of spouse & 32 & 3.8 & $3.19 \pm 0.82$ & & \\
\hline \multicolumn{6}{|l|}{ Professional position } \\
\hline Without professional title & 55 & 6.5 & $3.09 \pm 0.84$ & \multirow[t]{5}{*}{$F=5.190$} & \multirow[t]{5}{*}{$<0.001$} \\
\hline Resident physician & 224 & 26.6 & $3.26 \pm 0.97$ & & \\
\hline Attending physician & 242 & 28.7 & $3.55 \pm 0.98$ & & \\
\hline Associate chief physician & 184 & 21.9 & $3.58 \pm 0.99$ & & \\
\hline Chief Physician & 137 & 16.3 & $3.38 \pm 1.07$ & & \\
\hline \multicolumn{6}{|l|}{ Monthly income } \\
\hline$\leq 3000$ Yuan & 98 & 11.6 & $3.34 \pm 0.93$ & \multirow[t]{5}{*}{$F=0.643$} & \multirow[t]{5}{*}{0.632} \\
\hline 3001-6000 Yuan & 323 & 38.4 & $3.39 \pm 1.00$ & & \\
\hline 6001-9000 Yuan & 238 & 28.3 & $3.50 \pm 0.99$ & & \\
\hline 9001-20,000 Yuan & 157 & 18.6 & $3.43 \pm 1.03$ & & \\
\hline$\geq 20,000$ Yuan & 26 & 3.1 & $3.42 \pm 1.06$ & & \\
\hline
\end{tabular}




\section{Description results of Main variables}

All description results of the main variables in this study are presented in Table 2, which shows that participants reported that the self-perceived professional reputation damage of Chinese physicians is caused by groups including patients, their relatives, and the public. Approximately $83 \%$ of participants perceived negative social impressions from the public. Approach $47.3 \%$ participants reported that they had the turnover intention. Additionally, more than $70 \%$ of the participants disagreed or strongly disagreed with the prospect of their offspring becoming a physician. About $74.9 \%$ participants experienced a degree of stress. Three out of five participants reported low-level subjective well-being. Near $46.4 \%$ participants reported definitely burning out and had one or more symptoms of burnout, such as physical and emotional exhaustion, even experienced symptoms of burnout and completely burned out.

\section{Exploratory factor analysis and reliability analysis of the causes leading to self-perceived professional reputation damage of Chinese physicians}

Exploratory factor analysis was conducted to explore the structure of causes. Results reveal that the Bartlett spherical test coefficient is 0.000 , representing an obvious level of significance. The KMO coefficient is 0.957 , which is greater than 0.900 . The Bartlett spherical test illustrates that there are several common factors among the 32 projects.

As a primary result of the principal component analysis, two items should be deleted owing to their two mutual factors. Ultimately, the principal component analysis suggested a 4-factor structure, accounting for $64.11 \%$ of all variances $(21.86 \%$ by Factor $1,16.90 \%$ by Factor $2,14.06 \%$ by Factor 3, and $11.30 \%$ by Factor 4 ). The pattern and structures of the rotated common factors are shown in Table 3. The internal consistency reliability for the 30-item had an overall Cronbach's $\alpha$ coefficient of 0.950 . Moreover, the standardized factor loading of all the items ranges was above the threshold limit of 0.5 and above suggested by Hair et al. [36]. Internal consistency reliability analyses showed good internal consistency for all projects.

\section{Correlations among study variables}

The means, standard deviations, and Pearson correlation coefficients of continuous variables are shown in Table 4. As shown in the results, all variables were significantly correlated with each other. Self-perceived professional reputation damage was positively correlated with defensive medicine $(r=0.205, P<0.01)$, turnover intention $(r=0.253, P<0.01)$, career choice advice $(r=0.333, P<$ $0.01)$, perceived stress $(r=0.229, P<0.01)$, and burnout $(r=0.236, P<0.01)$ and was negatively correlated with subjective sense of well-being $(r=-0.343, P<0.01)$.

\section{Hierarchical linear regression models}

Two groups of hierarchical regression analyses were performed to examine the influence of self-perceived professional reputation damage on withdrawal behavior (Table 5) and workplace well-being (Table 6), after eliminating the effects of demographic variables.

As shown in Table 5, self-perceived professional reputation damage was positively associated with defensive medicine $(\beta=0.172, P<0.001)$. These results are also revealed in Table 5 . We find that self-perceived professional reputation damage was positively associated with turnover intention $(\beta=0.240, P<0.001)$. Moreover, a positive correlation between self-perceived professional reputation damage and career choice advice (i.e. as parents, Chinese physicians disapprove of their offspring becoming a physician when given a choice of occupation) was observed in the subjects $(\beta=0.332, P<0.001)$. The results suggest that self-perceived professional reputation damage of Chinese physicians was positively correlated with their withdrawal behaviors. So, the high level of physicians' self-perceived professional reputation damage is closely related to negative organizational behaviors and aversion to the occupation of a physician.

Correlation between self-perceived professional reputation damage among Chinese physicians and their workplace well-being also were tested, and all results are presented in Table 6. These results indicate that three hierarchical linear regression analyses all exhibited statistical significance. We found that self-perceived professional reputation damage was positively associated with perceived stress $(\beta=0.214, P<0.001)$ and job burnout $(\beta=0.209, P<0.001)$ and was negative associated with subjective sense of well-being $(\beta=-0.311, P<0.001)$. Therefore, the high level of physicians' self-perceived professional reputation damage is negatively related to workplace well-being.

\section{Discussion}

Chinese physicians were aware of severe self-perceived professional reputation damage

This study investigated the status of physicians' selfperceived professional reputation damage and its effect on several facets of organizational behavior and workplace well-being. A national study witnessed that the deteriorated patient-provider relationship has serious ramifications for physicians' public and self-perception in China [37]. Similarly, we further found that Chinese physicians have suffered widely from disrepute and stigmatization. About $83 \%$ of participants perceived professional reputation damage or estimation from patients, private citizens, and the general public. Chinese 
Table 2 Description information of main variables $(n=842)$

\begin{tabular}{|c|c|c|c|}
\hline Level & $\mathbf{n}$ & $\%$ & $\begin{array}{l}\text { accumulative } \\
\text { percent }\end{array}$ \\
\hline \multicolumn{4}{|l|}{ Self-perceived professional reputation damage } \\
\hline Very Positive & 13 & 1.5 & 1.5 \\
\hline Positive & 130 & 15.4 & 17.0 \\
\hline General & 334 & 39.7 & 56.7 \\
\hline Negative & 219 & 26.0 & 82.7 \\
\hline Very Negative & 146 & 17.3 & 100.0 \\
\hline \multicolumn{4}{|l|}{ Defensive Medicine } \\
\hline Never & 97 & 11.5 & 11.5 \\
\hline Very seldom & 300 & 35.6 & 47.1 \\
\hline Quite often & 286 & 34.0 & 81.1 \\
\hline Very often indeed & 126 & 15.0 & 96.1 \\
\hline Nearly all the time & 33 & 3.9 & 100.0 \\
\hline \multicolumn{4}{|l|}{ Turnover Intention } \\
\hline Not at all & 161 & 19.1 & 19.1 \\
\hline Very seldom & 283 & 33.6 & 52.7 \\
\hline Sometimes & 197 & 23.4 & 76.1 \\
\hline Often & 140 & 16.6 & 92.8 \\
\hline Nearly all the time & 61 & 7.2 & 100.0 \\
\hline \multicolumn{4}{|l|}{ Career choice advice (the attitude toward his/her offspring becoming a physician) } \\
\hline Strongly Agree & 12 & 1.4 & 1.4 \\
\hline Agree & 112 & 13.3 & 14.7 \\
\hline Neutral & 151 & 17.9 & 32.7 \\
\hline Disagree & 320 & 38.0 & 70.7 \\
\hline Strongly Disagree & 247 & 29.3 & 100.0 \\
\hline \multicolumn{4}{|l|}{ Perceived Stress } \\
\hline Not at all & 53 & 6.3 & 6.3 \\
\hline Not Often & 158 & 18.8 & 25.1 \\
\hline Sometimes & 320 & 38.0 & 63.1 \\
\hline Usually & 234 & 27.8 & 90.9 \\
\hline Definitely & 77 & 9.1 & 100.0 \\
\hline \multicolumn{4}{|l|}{ Subjective Well-being } \\
\hline Very unhappy & 37 & 4.4 & 4.4 \\
\hline Unhappy & 152 & 18.1 & 22.4 \\
\hline Uncertainty & 318 & 37.8 & 60.2 \\
\hline Happy & 314 & 37.3 & 97.5 \\
\hline Perfectly happy & 21 & 2.5 & 100.0 \\
\hline \multicolumn{4}{|l|}{ Burnout } \\
\hline I enjoy my work. I have no symptoms of burnout. & 22 & 2.6 & 2.6 \\
\hline Occasionally I am under stress, and I don't always have as much energy as I once did, but I don't feel burned out. & 429 & 51.0 & 53.6 \\
\hline $\begin{array}{l}\text { I am definitely burning out and have one or more symptoms of burnout, such as physical and emotional } \\
\text { exhaustion. }\end{array}$ & 202 & 24.0 & 77.6 \\
\hline The symptoms of burnout that I'm experiencing won't go away. I think about frustration at work a lot. & 126 & 15.0 & 92.5 \\
\hline $\begin{array}{l}\text { I feel completely burned out and often wonder if I can go on. I am at the point where I may need some changes } \\
\text { or may need to seek some sort of help. }\end{array}$ & 63 & 7.5 & 100.0 \\
\hline
\end{tabular}


Table 3 Rotated factor loading matrix of all items

\begin{tabular}{|c|c|}
\hline Items & $\begin{array}{l}\text { Factor } \\
\text { Loading }\end{array}$ \\
\hline \multicolumn{2}{|l|}{ Factor 1: Conflict transfer from the / an imperfect health system and changing society } \\
\hline Incompatible functions between health system and insurance, medical expenses are overburdening patients. & 0.769 \\
\hline $\begin{array}{l}\text { Government investment in healthcare industry is inadequate, while the reason for increasing medical expenses is often mistakenly } \\
\text { attributed to Chinese physicians. }\end{array}$ & 0.767 \\
\hline Imperfect salary structure in public hospitals results in a low reward of Chinese physicians. & 0.765 \\
\hline $\begin{array}{l}\text { The unclear boundary between the power and responsibility caused by a defective legal system result in increasing difficulty to } \\
\text { maintain the interests of both physicians and patients in China. }\end{array}$ & 0.749 \\
\hline Chinese physicians are overloaded owing to consulting with an excessive number of patients. & 0.713 \\
\hline High-quality resources are concentrated in the big cities, resulting in overcrowding in large hospitals. & 0.693 \\
\hline Current social trust is generally lower in China, which in turn exacerbates the gap in trust between the physicians and patients. & 0.684 \\
\hline Information regarding the negative reputation of physicians diffuses quickly in an internet era of easy interconnection. & 0.631 \\
\hline Public and media platforms are prone to ideologies of conspiracies and lack recognition for medical profession and clinicians. & 0.623 \\
\hline During this social transformation period, wide-ranging inequity triggers public dissatisfaction with all Chinese industries. & 0.558 \\
\hline \multicolumn{2}{|l|}{ Factor 2: Individual Deviance Behavior of Physicians } \\
\hline Physicians' Communication skill with patients is poor. & 0.806 \\
\hline The service attitude of some physicians is not good. & 0.803 \\
\hline The professionalism of some physicians is absent. & 0.775 \\
\hline Busy physicians are without enough time to care for their patients. & 0.770 \\
\hline Alert physicians often distrust their patients or their relatives. & 0.695 \\
\hline Pursuing the economic interests of some physicians leads to occasionally excessive diagnosis and treatment. & 0.688 \\
\hline Professional ability and skill Some physicians are deficient. & 0.688 \\
\hline \multicolumn{2}{|l|}{ Factor 3: Cognitive Bias of Social Public } \\
\hline Some patients or their relatives are hot-tempered and fail to cooperate with their physicians. & 0.771 \\
\hline Some patients or their relatives are biased and show distrust toward Chinese physicians. & 0.717 \\
\hline Social media used to promote reproachful narration toward Chinese physicians without professional or medical judgment. & 0.693 \\
\hline Some patients or their relatives often raise unreasonable expectations of their physician. & 0.683 \\
\hline $\begin{array}{l}\text { Social media used to pursue to sensational press or reports regarding physician-patient dispute event lead to magnified, distorted, } \\
\text { and amplified results. }\end{array}$ & 0.647 \\
\hline The patients or their relatives believe that either the physician or hospitals generate the result of Chinese high medical expenses. & 0.579 \\
\hline Chinese public hate to seek laws to deal with a medical error or accident. & 0.577 \\
\hline \multicolumn{2}{|l|}{ Factor 4: Improper Management in Public Hospital } \\
\hline Inadequate cooperation between different departments in Chinese public hospitals lends to low-efficiency management. & 0.769 \\
\hline $\begin{array}{l}\text { Due to poor procedure (awaiting long queues during many operations and steps such as registration, complications with } \\
\text { receiving a diagnosis and getting medicine) patients' time in consultation and treatment services is shortened. }\end{array}$ & 0.695 \\
\hline Hospitals pay much attention to economic benefits, which in turn increase patients' medical costs. & 0.626 \\
\hline Hospital management is not scientific and chaotic. & 0.614 \\
\hline Some hospitals' medical equipment and hardware are inadequate. & 0.611 \\
\hline The setting, operation, and medical institutions in public hospital are user-friendly. & 0.587 \\
\hline
\end{tabular}

physicians were subjected to a powerful stereotype by patients, who consider the physicians' profession rife with avaricious, indifferent, selfish, and insidious individuals. Unsurprisingly, there are widespread conflicts between physicians and patients, which further raise concerns about adverse narratives in the media and negative public opinion toward Chinese physicians, especially regarding their behavior and level of professionalism. Indeed, health care in China still faces huge challenges [38], such as a poor capacity of the primary health system, increasing expenditure, insufficient and incompetent personnel, inefficient use of resources, and other issues. As potential causes, the factors under study jointly exacerbated various conflicts between physicians 
Table 4 Means, standard deviation (SD) and correlations of continuous variables $(n=842)$

\begin{tabular}{lllllllll}
\hline Variables & Mean & SD & $\mathbf{1}$ & $\mathbf{2}$ & $\mathbf{3}$ & $\mathbf{4}$ & $\mathbf{5}$ & $\mathbf{6}$ \\
\hline 1. Self-perceived professional reputation damage & 3.42 & 1.00 & 1 & & & & & \\
2. Defensive medicine & 2.64 & 1.00 & $0.205^{* *}$ & 1 & & & & \\
3. Turnover intention & 2.59 & 1.18 & $0.253^{* *}$ & $0.220^{* *}$ & 1 & & & \\
4. Career choice advice & 3.81 & 1.05 & $0.333^{* *}$ & $0.082^{*}$ & $0.355^{* *}$ & 1 & & \\
5. Perceived stress & 3.15 & 1.03 & $0.229^{* *}$ & $0.199^{* *}$ & $0.467^{* *}$ & $0.234^{* *}$ & 1 & \\
6. Burnout & 2.74 & 1.00 & $0.236^{* *}$ & $0.259^{* *}$ & $0.537^{* *}$ & $0.294^{* *}$ & $0.551^{* *}$ & 1 \\
7. Well-being & 3.15 & 0.90 & $-0.343^{* *}$ & $-0.208^{* *}$ & $-0.493^{* *}$ & $-0.340^{* *}$ & $-0.402^{* *}$ & $-0.466^{* *}$ \\
\hline
\end{tabular}

Note: ${ }^{* *} p<0.01$, Pearson Correlation is significant at the 0.01 level (2-tailed)

and patients, as proven by current sample physicians. China is undergoing huge social change caused by rapid economic growth, which leads to the universal social conflicts existing in China today [32]. Thus, as an extension of the conflict, issues such as the distrust between people and disagreement concerning benefits between public and individual physicians are often present in the medical industry. In fact, there are some physicians with a low level of professionalism who exhibit individually deviant behavior [39], such as receiving 'redenvelope money', engaging in bribery, receiving kickbacks, and showcasing bad attitudes and lack of humanity in medicine [40]. Moreover, improper operations also exist in hospital management settings, including inadequate hospital institution, low efficiency of service, long queues for awaiting registration, lack of empathy, unreasonable bonus schemes [41], as well as profit-driven operation, management and performance assessment [37].
To avoid magnifying influence, hospital managers and health policy-makers used to compensate patients who engaged in 'YI NAO', even in the case where physicians or hospitals were without an accident. As a result, hospitals' response strategies to 'YI NAO' often motivate other patients and their families to follow unexpectedly. The increasing occurrence of 'YI NAO' has created negative opinions about Chinese public hospitals and physicians among the public and media. In addition, there is significant cognitive bias against Chinese physicians among patients and the general public, who allege that physicians do not master enough medical information of patients, and often are driven by economic interest, which contributes to a distrust of physicians' medical decision-making. Therefore, four chief factors (conflict transfer, cognitive bias, improper management, and individual deviance) were reported by Chinese physicians by current survey as reasons leading to physician's damaged professional reputation. To some extent,

Table 5 Hierarchical linear regression models for withdrawal behaviors

\begin{tabular}{|c|c|c|c|c|c|c|}
\hline \multirow[t]{2}{*}{ Variables } & \multicolumn{2}{|c|}{ Defensive medicine } & \multicolumn{2}{|c|}{ Turnover intention } & \multicolumn{2}{|c|}{ Career choice advice } \\
\hline & $\overline{M_{1}(\beta)}$ & $M_{2}(\beta)$ & $\overline{M_{3}(\beta)}$ & $M_{4}(\beta)$ & $\overline{M_{5}(\beta)}$ & $M_{6}(\beta)$ \\
\hline \multicolumn{7}{|l|}{ Control variables } \\
\hline Age & 0.117 & 0.129 & -0.083 & -0.067 & -0.119 & -0.096 \\
\hline Sex & -0.242 & $-0.224^{* *}$ & -0.013 & 0.012 & 0.011 & 0.046 \\
\hline Marital status & -0.023 & -0.028 & 0.015 & 0.007 & -0.010 & -0.021 \\
\hline Service Years & 0.079 & 0.073 & 0.079 & 0.071 & -0.007 & -0.019 \\
\hline Hospital level & -0.012 & 0.000 & 0.058 & $0.075^{*}$ & -0.026 & -0.003 \\
\hline Education level & 0.048 & 0.035 & -0.038 & -0.057 & -0.049 & $-0.075^{*}$ \\
\hline Professional title & -0.050 & -0.065 & 0.077 & 0.055 & 0.117 & 0.087 \\
\hline Monthly income & -0.052 & -0.025 & $-0.173^{* * *}$ & $-0.134^{* * *}$ & $-0.127^{*}$ & -0.074 \\
\hline \multicolumn{7}{|l|}{ Independent variable } \\
\hline Self-perceived professional reputation damage & & $0.172^{* * *}$ & & $0.240^{* * *}$ & & $0.332^{* *}$ \\
\hline F & $9.471^{* * *}$ & $11.552^{* * *}$ & $4.646^{* * *}$ & $9.940^{* * *}$ & $2.486^{*}$ & $13.443^{* * *}$ \\
\hline$R^{2}$ & $0.083^{* * *}$ & $0.111^{* * *}$ & $0.043^{* * *}$ & $0.097^{* * *}$ & $0.023^{*}$ & $0.127^{* * *}$ \\
\hline$\Delta R^{2}$ & $0.083^{* * *}$ & $0.028^{* * *}$ & $0.043^{* * *}$ & $0.054^{* * *}$ & $0.023^{*}$ & $0.104^{* * *}$ \\
\hline
\end{tabular}

Notes- $M_{1}, M_{3}, M_{5}$ : the influence of demographic variables on the Defensive medicine, Turnover intention and Career choice advice; $M_{2} M_{4} M_{6}$ : the influence of Selfperceived professional reputation damage on on the Defensive medicine, Turnover intention and Career choice advice; Notes-hierarchical linear regression ${ }^{*} p<$ 0.05 (2-tailed), ${ }^{* *} p<0.01$ (2-tailed), ${ }^{* * *} p<0.001$ (2-tailed) 
Table 6 Hierarchical linear regression models for workplace well-being

\begin{tabular}{|c|c|c|c|c|c|c|}
\hline \multirow[t]{2}{*}{ Variables } & \multicolumn{2}{|c|}{ Perceived stress } & \multicolumn{2}{|l|}{ Burnout } & \multicolumn{2}{|c|}{ Well-being } \\
\hline & $M_{7}(\beta)$ & $M_{8}(\beta)$ & $M_{9}(\beta)$ & $M_{10}(\beta)$ & $M_{11}(\beta)$ & $M_{12}(\beta)$ \\
\hline \multicolumn{7}{|l|}{ Control variables } \\
\hline Age & -0.114 & -0.100 & -0.016 & -0.002 & 0.089 & 0.068 \\
\hline Sex & $-0.072^{*}$ & -0.050 & $-0.118^{* *}$ & $-0.096^{* *}$ & $0.125^{* * *}$ & $0.092^{* *}$ \\
\hline Marital status & $0.094^{*}$ & $0.087^{*}$ & 0.037 & 0.030 & 0.030 & 0.040 \\
\hline Service Years & 0.022 & 0.015 & -0.050 & -0.058 & 0.011 & 0.022 \\
\hline Hospital level & 0.025 & 0.040 & -0.020 & -0.006 & -0.012 & -0.033 \\
\hline Education level & -0.009 & -0.026 & 0.026 & 0.010 & 0.011 & 0.035 \\
\hline Professional title & 0.057 & 0.038 & 0.028 & 0.009 & $-0.179^{* *}$ & $-0.151^{*}$ \\
\hline Monthly income & $-0.106^{* *}$ & $-0.072^{*}$ & $-0.131^{* * *}$ & $-0.098^{* *}$ & $0.179^{* * *}$ & $0.130^{* * *}$ \\
\hline \multicolumn{7}{|l|}{ Independent variable } \\
\hline Self-perceived professional reputation damage & & $0.214^{* * *}$ & & $0.209^{* * *}$ & & $-0.311^{* * *}$ \\
\hline$F$ & $2.703^{* *}$ & $6.776^{* * *}$ & $3.726^{* * *}$ & $7.549^{* * *}$ & $6.442^{* * *}$ & $16.201^{* * *}$ \\
\hline$R^{2}$ & $0.025^{* *}$ & $0.068^{* * *}$ & $0.035^{* * *}$ & $0.075^{* * *}$ & $0.058^{* * *}$ & $0.149^{* * *}$ \\
\hline$\Delta R^{2}$ & $0.025^{* *}$ & $0.043^{* * *}$ & $0.035^{* * *}$ & $0.041^{* * *}$ & $0.058^{* * *}$ & $0.091^{* * *}$ \\
\hline
\end{tabular}

Notes- $M_{7}, M_{9}, M_{11}$ : the influence of demographic variables on the Perceived stress, Burnout and Well-being; $M_{8}, M_{10}, M_{12}$ : the influence of Self-perceived professional reputation damage on the Perceived stress, Burnout and Well-being; Notes-hierarchical linear regression ${ }^{*} p<0.05\left(2\right.$-tailed), ${ }^{* *} p<0.012$-tailed), ${ }^{* * *}$ $p<0.001$ (2-tailed)

this study not only gives comprehensive answers regarding the degree of self-perceived professional reputation damage among Chinese physicians, it can also serve as a proposal to destigmatize the profession and promote the reform of China's health system. An honest statement of fact about social phenomenon of 'YI NAO' in China is beyond the scope of current study. Moreover, it must be mentioned that potential biasness present in the current study due to the collection way of the data collected by using the online resources were prone to obtain the evidence was rather limited.

Additionally, the current study also indicated that approach a half of participants exhibited the idea of turnover intention and one or more symptoms of burnout. More serious, about $74.9 \%$ participants experienced a degree of stress. Moreover, three out of five participants reported low-level subjective well-being. Above these findings are similar conclusions with other report's [42], which together imply that Chinese physicians are suffering from the increasingly serious occupational environment and awful well-being. In this case, more than $70 \%$ of the participants disapproved of their offspring becoming a physician, which also is a novel finding from current study. This worsening trend is threatening the entire health system, especially to physician personnel, which needs to catch the attention of health policy-makers in China.

Physicians' self-perceived professional reputation damage was positively associated to withdrawn behavior

We further found the significant associations between physicians' self-perceived professional reputation damage and withdrawn behavior and workplace well-being. Current findings revealed that self-stigmatized physicians are more likely to practice high-frequent defensive medicine, greater turnover intention, and more likely disapprove of offspring becoming a physician.

Physicians' self-perceived professional reputation damage results in a high risk for themselves in regard to interactions between physician and patient, which further contributes to a curious phenomenon that physicians being faced with a number of challenges when using the quality of patient-provider relationship as a toolkit for decision-making [43]. Furthermore, when some patients are regarded as potential troublemakers who are likely to present a high risk of 'Yi Nao,' more defensive medicine will be practiced by physicians toward them to protect themselves avoiding being attacked [44]. Undoubtedly, the social reputation and status of physicians group are gradually weakened in China, which tends to present the healthcare industry as unattractive, further increasing turnover among physicians. Most importantly, current survey supported the fact that new generations of Chinese physicians are likely to face a crisis [45]. Additionally, these physicians had reported that they regretted entering the medical profession and attempted to leave it [46]. The current study also observed that physicians' experience of damaged professional reputation led them to identify their career as negative and prevented them from encouraging the next generation to become physicians, hampering recruitment of young physicians among medical graduates [47]. Based on analysis results, $38.0 \%$ and $29.3 \%$ of 
participants disagree and strongly disagree, respectively, with the prospect of their offspring becoming physicians. Similarly, another more serious phenomenon needs to be concerned that since physician suicide was a significant problem, i.e., male doctors had suicide rates as much as $40 \%$ higher than the general population, female doctors up to $130 \%$ higher [48], and that cross-sectional findings demonstrated higher rates of depression in medical trainees compared to the general population [49], which seems to be ignored due to systemic barriers that discourage self-care and help-seeking behaviors among physicians. This shocking discovery should stimulate China's central government to pay more attention to Chinese physicians' salaries, social status, workplace well-being, and dignity. Those offensive or prejudicial assessments on Chinese health profession and industry as a social stereotype are hurting physicians' well-being and health. On the one hand, future studies should pay attention to explore the rates of psychiatric disorders, e.g., anxiety, depression, and suicidality among physicians and if they actually sought professional assistance. On the other hand, a positive, respectful and friendly professional reputation toward Chinese physician community is urgent for building a better health system, which has been neglected severely and slipped out the opinion of health policy-makers and practitioners.

\section{Self-perceived professional reputation damage was negatively associated to workplace well-being of Chinese physicians}

This study outlined that stigmatized physicians experienced a lower level of workplace well-being, such as high perceived stress, increasing burnout, and decline in the subjective sense of well-being.

Stigmatized physicians were troubled by the distrustful relationship between physicians and patients in China, which led them to devote more energy to deal with interpersonal communication with patients and their families, representing a psychological expense and loss of psychological resources owing to the loss (or risk of loss) of patients' trust and dignity. The risk of a physicians' loss of professional reputation is a source of pressure. Admittedly, Chinese patient-provider relationship has historically been poor, which causes increasing physicians' damaged reputation, perceived stress, and burnout. Thus, we can further argue that there are positive associations between tense patient-provider relationship, self-perceived professional reputation damage, perceived stress, and burnout. Similarly, subjective sense of wellbeing of stigmatised physicians certainly will be compromised. Overall, physicians' self-perceived professional reputation damage was associated with low workplace well-being, which emphasizes a suggestion for health policy-makers and practitioners that maintaining physicians' positive social image is a benefit for accelerating their health and wellness.

\section{Limitations}

Some limitations must be acknowledged. First, a convenience sample was used in this study, which increased the potential for sampling bias. Second, a major limitation of the study is the cross-sectional design, whose nature cannot effectively and precisely judge the causal relationship between the variables. One important direction for future research involves longitudinal studies. Third, the data were collected from self-reports from physicians by means of an online survey, which is likely to introduce response bias from social desirability or negative affection. The physicians might have overestimated or underestimated the association between the study's variables. Moreover, several single-item tools in this study were used for collecting the data in order to abbreviate survey material and potentially increase response rates, but which potentially reduce the validity and reliability of this measurement; therefore, a widely used measure tool should be adopted in the future.

\section{Conclusions}

The current study enhances the knowledge by investigating the status of self-perceived professional reputation damage of Chinese physicians and its association with withdrawal behaviors and workplace well-being.

Physicians with a high level of self-perceived professional reputation damage were more likely to practice defensive medicine from avoiding the risk of suffering medical dispute. This study broadens the understanding of the nature of the association between patient-provider relationship and defensive behaviors. Physicians practice defensively because of self-perceived threats caused by self-perceived professional reputation damage arising from tense physician- patient relationships.

Physicians who experience a high level of selfperceived professional reputation damage are more likely to quit or disapprove of their offspring becoming physicians. Meanwhile, current study already demonstrated that Chinese physicians universally were suffering from high-intention turnover, high-level stress, great-risk burnout, low-level subjective well-being, and were unreluctant to support their offspring becoming a physician. These findings are a meaningful reminder for policymakers to formulate policies to encourage qualified personnel to enter the Chinese health system.

Four potential reasons for physicians' damaged professional reputation were clarified by using an exploratory factor analysis, which includes conflict transfer, cognitive bias, improper management, and individual deviance. This category contributes to the preliminary literature 
by supplying a better understanding of potential reasons for conflicts between physicians and patients, especially as these conflicts relate to the topic of health system reform in China.

In addition, a negative association between selfperceived professional reputation damage of Chinese physicians and workplace well-being was illustrated, which demonstrated that physicians with a high level of self-perceived professional reputation damage also suffer greater perceived stress and burnout and a reduced subjective sense of well-being. This finding indirectly indicates that poor patient-provider relationships threaten physicians' mental health and well-being through physicians' increasing self-self-perceived professional reputation damage.

Finally, we advocate for interventions to reduce physicians' damaged professional reputation, which will, directly or indirectly, protect physicians' benefits and wellbeing. Physicians' professional reputation management strategies should be proposed in future. A favourable public opinion environment towards the medical industry and its health care staff will contribute to improved patient-provider relationships, which will promote effective health system reform.

\section{Abbreviations \\ AIDS: Acquired Immune Deficiency Syndrome; ADHD: Attention Deficit Hyperactivity Disorder; ECHMU: Ethics Committee of Harbin Medical University; ANCOVA: Analysis of Covariance; KMO: Kaiser-Meyer-Olkin; M: Mean; SD: Standard Deviation}

\section{Supplementary Information}

The online version contains supplementary material available at https://doi. org/10.1186/s12913-021-06306-6.

\section{Additional file 1.}

\section{Acknowledgments}

The authors give our sincerely thanks to all participants who have helped collecting data and distributing questionnaires to other subjects. The author also thanks Editage for its English language service.

\section{Authors' contributions}

Conceived and designed the experiments: TS JW. Performed the experiments: TS SZ. Analyzed the data: TS JW SZ YS. Contributed reagents/ materials/analysis tools: TS JW YS XW. Wrote the paper: TS BL. Approved the final manuscript for publication: TS BL XW. All authors have read and approved the manuscript.

\section{Funding}

This work was supported by the National Natural Science Foundation (No. 71774045) and Scientific Research Start-up Funding of Hangzhou Normal University (No. 2019QDL038). The funding body had no role in the design of the study and collection, analysis, and interpretation of data and in writing the manuscript.

\section{Availability of data and materials}

Data is currently not available online, but the data can be obtained upon request from hydsuntao@126.com.

\section{Declarations}

\section{Ethics approval and consent to participate}

All procedures in this survey involving human participants were in accordance with the ethical standards of the institutional and committee (The Institutional Review Board of Harbin Medical University). Due to the anonymous survey approach, written informed consent could not be obtained. A verbal informed consent form was included at the beginning of the questionnaire. And the ethics committee had approved verbal consent for this study. Completing the questionnaire regarded as a verbal consent was therefore considered 'informed consent' for participation in the survey.

\section{Consent for publication}

No applicable.

\section{Competing interests}

There are no competing interests to declare.

\section{Author details}

'Department of Health Management to School of Medicine, Hang Zhou Normal University, No.2318 Yuhangtang Road, Cangqian Street, Yuhang District, Hangzhou City 311121, Zhejiang Province, China. ${ }^{2}$ College of Health Management of Harbin Medical University, Harbin 150086, China.

${ }^{3}$ Department of Epidemiology and Health Statistics, School of Public Health, Peking University, Beijing 100191, China.

Received: 7 September 2020 Accepted: 22 March 2021

Published online: 14 April 2021

\section{References}

1. Yip W, Hsiao W. Harnessing the privatisation of China's fragmented healthcare delivery. Lancet. 2014;384(9945):805-18. https://doi.org/10.1016/501406736(14)61120-X.

2. Winnie Y, Hongqiao F, Chen AT, Tiemin Z, Weiyan J, Roman X, et al. 10 years of health-care reform in China: progress and gaps in Universal Health Coverage. Lancet (London, England). 2019;394:1192-204.

3. Li Y, Malik V, Hu FB. Health insurance in China: after declining in the 1990s, coverage rates rebounded to near-universal levels by 2011. Health Aff. 2017; 36(8):1452-60. https://doi.org/10.1377/hlthaff.2016.1658.

4. The L. China through the lens of health in 2018 and beyond. Lancet. 2018; 391(10125):999.

5. The L. A tiered health-care delivery system for China. Lancet. 2019; 393(10177):1178.

6. Yip W, Hsiao WC. The Chinese health system at a crossroads. Health Aff. 2008;27(2):460-8. https://doi.org/10.1377/hlthaff.27.2.460.

7. Brendan MC, Jan D, Liz B, Ann CN, Kate K, Mary M, et al. Developing personcentred practice: nursing outcomes arising from changes to the care environment in residential settings for older people. Int J Older People Nursing. 2010;5(2):93-107.

8. Zhao J, Gao S, Wang J, Liu X, Hao Y. Differentiation between two healthcare concepts: person-centered and patient-centered care. J Nursing. 2016;3(4): 398-402.

9. Lancet T. Chinese doctors are under threat. Lancet. 2010;376(9742):657. https://doi.org/10.1016/S0140-6736(10)61315-3.

10. Pan $Y$, Yang $X$, He JP, Gu YH, Zhan XL, Gu HF, et al. To be or not to be a doctor, that is the question: a review of serious incidents of violence against doctors in China from 2003-2013. J Public Health. 2015;23(2):111-6. https:/ doi.org/10.1007/s10389-015-0658-7.

11. Lo D, Wu F, Chan M, Chu R, Li D. A systematic review of burnout among doctors in China: a cultural perspective. Asia Pac Fam Med. 2018;17(1):1-13.

12. Jing $W$, Otten $H$, Sullivan $L$, Lovellsimons $L$, Granekcatarivas $M$, Fritzsche $K$. Improving the doctor-patient relationship in China: the role of Balint groups. Int J Psychiatry Med. 2013;46(4):417-27. https://doi.org/10.2190/PM.4 6.4.g.

13. Zhou M, Zhao L, Campy KS, Wang S. Changing of China's health policy and doctor-patient relationship: 1949-2016. Health Policy Technol. 2017;6(3): 358-67. https://doi.org/10.1016/j.hlpt.2017.05.002.

14. Sun T, Gao L, Li F, Shi Y, Xie F, Wang J, et al. Workplace violence, psychological stress, sleep quality and subjective health in Chinese doctors: a large cross-sectional study. BMJ Open. 2017;7(12):e017182. https://doi. org/10.1136/bmjopen-2017-017182. 
15. Jiao M, Ning N, Li Y, Gao L, Cui Y, Sun H, et al. Workplace violence against nurses in Chinese hospitals: a cross-sectional survey. BMJ Open. 2015;5(3): e006719. https://doi.org/10.1136/bmjopen-2014-006719.

16. Zhao S-H, Shi Y, Sun Z-N, Xie F-Z, Wang J-H, Zhang S-E, et al. Impact of workplace violence against nurses' thriving at work, job satisfaction and turnover intention: a cross-sectional study. J Clin Nurs. 2018;27(13-14):262032. https://doi.org/10.1111/jocn.14311.

17. Zhang S-E, Liu W, Wang J, Shi Y, Xie F, Cang S, et al. Impact of workplace violence and compassionate behaviour in hospitals on stress, sleep quality and subjective health status among Chinese nurses: a cross-sectional survey. BMJ Open. 2018;8(10):e019373. https://doi.org/10.1136/bmjopen-2017-0193 73.

18. Liu W, Zhao S, Shi L, Zhang Z, Liu X, Li L, et al. Workplace violence, job satisfaction, burnout, perceived organisational support and their effects on turnover intention among Chinese nurses in tertiary hospitals: a crosssectional study. BMJ Open. 2018;8(6):e019525. https://doi.org/10.1136/ bmjopen-2017-019525.

19. Zhao S, Xie F, Wang J, Shi Y, Zhang S, Han X, et al. Prevalence of workplace violence against Chinese nurses and its association with mental health: a cross-sectional survey. Arch Psychiatr Nurs. 2018;32(2):242-7. https://doi. org/10.1016/j.apnu.2017.11.009.

20. Lanctôt N, Guay S. The aftermath of workplace violence among healthcare workers: a systematic literature review of the consequences. Aggress Violent Behav. 2014;19(5):492-501. https://doi.org/10.1016/j.avb.2014.07.010.

21. Hesketh T, Wu D, Mao L, Ma N. Violence against doctors in China. Bmj. 2012;345(sep07 1):e5730. https://doi.org/10.1136/bmj.e5730.

22. Cao J, Wei J. Evolution of the perception of the doctor's role in China. Lancet. 2014;384(9945):742. https://doi.org/10.1016/S0140-6736(14)61432-X.

23. Yang Z, Fan D. How to solve the crisis behind Bribegate for Chinese doctors. Lancet. 2012;379(9812):e13-5. https://doi.org/10.1016/S0140-673 6(11)60137-2.

24. Wu D, Hesketh T, Zhou X-D. Media contribution to violence against health workers in China: a content analysis study of 124 online media reports. Lancet. 2015;386(Special Issue):S81. https://doi.org/10.1016/S0140-6736(1 5)00662-5.

25. Prabhu AV, Kim C, De Guzman E, Zhao E, Madill E, Cohen J, et al. Reputation management and content control: an analysis of radiation oncologists' digital identities. Int J Radiation Oncol Biol Physics. 2017;99(5):1083-91.

26. Lebowitz MS. Stigmatization of ADHD: a developmental review. J Atten Disord. 2016;20(3):199-205. https://doi.org/10.1177/1087054712475211.

27. Lyndon AE, Crowe A, Wuensch KL, McCammon SL, Davis KB. College students' stigmatization of people with mental illness: familiarity, implicit person theory, and attribution. J Ment Health. 2019;28(3):255-9. https://doi. org/10.1080/09638237.2016.1244722.

28. Courtwright A, Turner AN. Tuberculosis and stigmatization: pathways and interventions. Public Health Rep. 2012;125(4_suppl):34-42.

29. Ernst J, Mehnert A, Taubenheim S, Rentsch A, Hornemann B, Esser P. Stigmatization in employed patients with breast, intestinal, prostate and lung cancer. Psychother Psychosom Med Psychol. 2017;67(7):304-11.

30. Brohan E, Slade M, Clement S, Thornicroft G. Experiences of mental illness stigma, prejudice and discrimination: a review of measures. BMC Health Serv Res. 2010;10(1):80. https://doi.org/10.1186/1472-6963-10-80.

31. Meisenbach RJ. Stigma management communication: a theory and agenda for applied research on how individuals manage moments of stigmatized identity. J Appl Commun Res. 2010;38(3):268-92. https://doi.org/10.1080/ 00909882.2010.490841.

32. Zhang R, Noels KA, Guan Y, Weng L. Making sense of positive selfevaluations in China: the role of sociocultural change. Eur J Soc Psychol. 2016;47(1):36-52

33. Leung SO, Xu ML. Single-item measures for subjective academic performance, self-esteem, and socioeconomic status. J Soc Serv Res. 2013; 39(4):511-20. https://doi.org/10.1080/01488376.2013.794757.

34. Elo $A-L$, Leppänen $A$, Jahkola A. Validity of a single-item measure of stress symptoms. Scand J Work Environ Health. 2003:2003:444-51.

35. Rohland BM, Kruse GR, Rohrer JE. Validation of a single-item measure of burnout against the Maslach burnout inventory among physicians. Stress Health. 2004;20(2):75-9. https://doi.org/10.1002/smi.1002.

36. Hair JF, Black B, Babin BJ, Anderson R. Multivariate data analysis. 7th ed. Upper Saddle River: Pearson Prentice Hall; 2009.

37. Zhang $P$, Wang F, Cheng Y, Zhang LY, Ye BZ, Jiang HW, et al. Impact of organizational and individual factors on patient-provider relationships: a national survey of doctors, nurses and patients in China. PLoS One. 2017; 12(7):e0181396. https://doi.org/10.1371/journal.pone.0181396.

38. Meng Q, Mills A, Wang L, Han Q. What can we learn from China's health system reform? BMJ. 2019;365:12349.

39. Hougaard JL, Østerdal LP, Yu Y. The Chinese healthcare system. Appl Health Econ Health Policy. 2011;9(1):1-13. https://doi.org/10.2165/11531800000000000-00000

40. Wang F, Song Z, Zhang W, Xiao Y. Medical humanities play an important role in improving the doctor-patient relationship. Biosci Trends. 2017;11(2): 134-7. https://doi.org/10.5582/bst.2017.01087.

41. Qian J, He AJ. The Bonus scheme, motivation crowding-out and quality of the doctor-patient encounters in Chinese public hospitals. Public Org Rev. 2018;18(2):143-58. https://doi.org/10.1007/s11115-016-0366-y.

42. Zhang S, Wang J, Xie F, Yin D, Shi Y, Zhang M, et al. A cross-sectional study of job burnout, psychological attachment, and the career calling of Chinese doctors. BMC Health Serv Res. 2020;20(1):193. https://doi.org/10.1186/s12 913-020-4996-y.

43. Diamond-Brown L. The doctor-patient relationship as a toolkit for uncertain clinical decisions. Soc Sci Med. 2016;159(2016):108-15. https://doi.org/10.101 6/j.socscimed.2016.05.002.

44. Li H, Wu X, Sun T, Li L, Zhao X, Liu X, et al. Claims, liabilities, injures and compensation payments of medical malpractice litigation cases in China from 1998 to 2011. BMC Health Serv Res. 2014;14(1):1-9.

45. Jie L. New generations of Chinese doctors face crisis. Lancet. 2012; 379(9829):1878. https://doi.org/10.1016/S0140-6736(12)60774-0.

46. Tian J, Du L. Microblogging violent attacks on medical staff in China: a case study of the Longmen County People's hospital incident. BMC Health Serv Res. 2017;17(1):363. https://doi.org/10.1186/s12913-017-2301-5.

47. Gaebel W, Zäske H, Cleveland H-R, Zielasek J, Stuart H, Arboleda-Florez J, et al. Measuring the stigma of psychiatry and psychiatrists: development of a questionnaire. Eur Arch Psychiatry Clin Neurosci. 2011;261(2):119-23. https://doi.org/10.1007/s00406-011-0252-0.

48. Schernhammer E. Taking their own lives - the high rate of physician suicide. N Engl J Med. 2005;352(24):2473-6. https://doi.org/10.1056/ NEJMp058014.

49. Center C, Davis M, Detre T, Ford DE, Hansbrough W, Hendin H, et al. Confronting depression and suicide in physicians: a consensus statement. JAMA. 2003;289(23):3161-6. https://doi.org/10.1001/jama.289.23.3161.

\section{Publisher's Note}

Springer Nature remains neutral with regard to jurisdictional claims in published maps and institutional affiliations.
Ready to submit your research? Choose BMC and benefit from:
- fast, convenient online submission
- thorough peer review by experienced researchers in your field
- rapid publication on acceptance
- support for research data, including large and complex data types
- gold Open Access which fosters wider collaboration and increased citations
- maximum visibility for your research: over $100 \mathrm{M}$ website views per year
At BMC, research is always in progress.
Learn more biomedcentral.com/submission 